\title{
Übermensch: a interpretação nietzschiana de ultrapassamento
}

\section{Übermensch: the nietzschean interpretation of overtaking}

Eduardo Marcos Silva de Oliveira ${ }^{1}$

\section{Resumo}

Pretende-se com o presente artigo $^{2}$ apresentar a última figura de exceção na filosofia nietzschiana, o além do homem, descrevendo-a como o objetivo a ser alcançado pelo homem. Dessa forma, optamos por desenvolver este artigo enfatizando a definição de uma das figuras mais relevantes de sua produção filosófica, o Übermensch. Expressão que sintetiza a definição nietzschiana da busca pelo ultrapassamento do homem e, concomitantemente, por uma nova concepção de valores em sua filosofia. Analisando este conceito, que é introduzido na obra nietzschiana a partir dos escritos de Assim falou Zaratustra, o texto se desenvolve sobre a compreensão do autor de vontade de potência e eterno retorno, e como essa significação é descrita como uma possibilidade, segundo Nietzsche, de superação do homem frente ao niilismo.

Palavras-chave: Übermensch; Vontade de Potência; Eterno Retorno; Niilismo; Ultrapassamento.

\begin{abstract}
It is intended with this article to present the last figure of exception in Nietzschean philosophy, the above-human, describing it as the goal to be achieved by man. That way, we chose to develop this article emphasizing the definition of one of the most relevant figures of his philosophical production, the Übermensch. Expression that synthesizes the Nietzschean definition of the search for the overtaking of man and, concomitantly, for a new conception of values in his philosophy. Analyzing this concept, which is introduced in Nietzsche's work from the writings of Thus Spoke Zarathustra, the text develops on the author's understanding of power will and eternal return, and how this meaning is
\end{abstract}

\footnotetext{
${ }^{1}$ Mestre em Ciências da Religião pela PUC Minas. E-mail: edumasilo@gmail.com

${ }^{2} \mathrm{O}$ trabalho apresentado é parte dos estudos realizados sobre a filosofia da religião em Nietzsche, sobre orientação do professor Flávio Augusto Senra Ribeiro. Para nos orientarmos sobre as chamadas das obras nietzschianas, recorreremos a organização do original sugerida pela edição das Obras Completas de Colli/Montinari em Sämtliche Werke. Kritische Studienausgabe (KSA). Herausgegeben von Giorgio Colli und Mazzino Montinari. München/Berlin/New York: dtv/Walter de Gruyter \& Co., 1988. As demais obras serão apresentadas segundo as normas técnicas brasileiras.
} 
Religare, ISSN: 19826605, v.15, n.1, agosto de 2018, p.308-323.

described as a possibility, according to Nietzsche, of overcoming man in the face of nihilism.

Keywords: Übermensch; Will to Power; Eternal Return; Nihilism; Overtaking.

\section{Introdução}

Nietzsche, ao longo de sua produção filosófica, busca compreender a cultura da modernidade através de um processo investigativo e diagnostica dois determinados $\operatorname{tipos}^{3}$ de vida, ficando mais elucidadas essa definição em sua obra Ecce Homo, propensas a um niilismo afirmativo ou ao niilismo negativo. $\mathrm{Na}$ primeira fase de sua produção, na obra $O$ nascimento da tragédia ${ }^{4}$, encontra-se o gênio dionisíaco e sua capacidade de criação contrapondo-se ao gênio apolíneo que se estrutura na "justa medida". Na segunda fase, também descrita como intermediária, é apontado, por um lado, os espíritos livres caracterizados por buscar afirmar à vida, libertando-se de dogmas e valores determinados e aceitando os impasses que a vida possa acarretar, sendo que através de seu "páthos da distância" (GM/GM, I, § 2) dos conceitos modernistas e dos princípios tradicionais da cultura, cria valores e encontram-se tendentes a vivenciarem um niilismo afirmativo. Do outro, a religião como ocasionadora do processo de decadência da sociedade, criadora de espíritos aprisionados que proporciona uma vida doente (EH/EH, Por que sou tão sábio, § 6) a seus adeptos, caracterizada

\footnotetext{
${ }^{3}$ Segundo Silva (2008), fatores de suma importância nas obras de Nietzsche é sua compreensão sobre personagens históricos e literários para exemplificar suas ideias. Desta forma, sua problematização avança sobre as formas de valoração e seus tipos são apresentados como forma de exemplificação. Com esse método, Nietzsche descreve através de sua tipologia uma abrangente compreensão do homem. Este apontamento figura tanto no campo filosófico, quanto cultural, psicológico e moral. No desenvolver de sua filosofia, Nietzsche busca exemplificar novos tipos como princípio valorativo que representam diferentes naturezas humanas, sempre possíveis de transformação.

${ }^{4}$ É importante ressaltar que o termo niilismo não é apresentado em $O$ nascimento da tragédia . Aqui, a expressão se encontra no sentido de vontade de nada, que, no transcorrer do pensamento nietzschiano, será interpretado como niilismo negativo. O niilismo descrito por Nietzsche sobre O nascimento da tragédia é um afirmativo, como definido pelo filósofo em Ecce Homo. Essa descrição faz-se necessária para melhor compreender as tipologias e figuras de exceção que acompanham a produção filosófica nietzschiana.
} 
Religare, ISSN: 19826605, v.15, n.1, agosto de 2018, p.308-323.

por uma vontade fraca e um sentimento de culpabilidade com valores determinados, conveniente a sua estruturação e direcionados por um niilismo negativo. Por fim, na terceira e última fase de sua produção filosófica, Nietzsche (Cf. Za/ZA; GM/GM) descreve os homens superiores como detentores da arte, da política e das pretensões sociais capazes de buscar o acabamento da sociedade e criar novos valores contrapondo-se ao último homem que não cria e se anula.

Como não é possível, num artigo, abordar todo o sistema filosófico do nosso autor, por este motivo, ocupar-nos-emos em discorrer somente sobre a última etapa de seu pensamento distinguida pela abordagem do além do homem $^{5}$. Devido ao exposto, apresentamos o seguinte problema: o que seria o além do homem nietzschiano em contraposto aos paradigmas de uma sociedade cristianizada? A fim de responder essa premissa, procuraremos abordar a questão de ultrapassamento, segundo a interpretação de Nietzsche, como possibilidade de afirmação da vida e da potencialidade do homem de criar e destruir, de afirmar e negar e de transvalorar os valores da tradição judaicocristã.

\section{Übermensch: o ensinamento de Zaratustra}

Quando Nietzsche escreve Assim falou Zaratustra, dando início ao último período de sua filosofia, ele o faz tendo como referência incondicional de suas críticas o homem moderno perante sua condição de submissão aos valores tradicionais e a religião cristã. Nessa apreciação, afirma Nietzsche que tais valores representam

um determinado senso de crueldade, contra si mesmo e os outros; o ódio aos que pensam diferentemente; a vontade de

\footnotetext{
${ }^{5}$ A opção por traduzir o termo Übermensch por além do homem e não por super-homem, mantendo esta tradução apenas nas citações realizadas, faz-se devido acreditarmos que esta tradução melhor corresponde ao significado do termo. Inicialmente, entende-se pelo prefixo über um ir-além de, sobre, supra, acima de, sendo que, para Nietzsche, a expressão além do homem não se refere a de um mito no qual se superaria a humanidade em sua derrocada, mas de um potencial do homem que jamais teria sido concretizado.
} 
Religare, ISSN: 19826605, v.15, n.1, agosto de 2018, p.308-323.

perseguir. [...] Cristã é a hostilidade de morte aos senhores da Terra, aos "nobres" [...]. Cristão é o ódio ao espírito, ao orgulho, coragem, liberdade, libertinage do espírito; cristão é o ódio aos sentidos, às alegrias dos sentidos, à alegria mesma (AC/AC, § 21).

Essa última fase da filosofia nietzschiana é compreendida, segundo Almeida (2007), como o período em que melhor são esclarecidos os conceitos e as avaliações em torno da vontade de potência ${ }^{6}$ (Wille zur Macht). É representada também pelas obras $O$ anticristo, Além do bem e do mal e Genealogia da moral, caracterizando o posicionamento determinante da filosofia nietzschiana frente aos valores do homem moderno.

Poder-se-ia definir Nietzsche nesse período em dois aspectos distintos ao descrever seu Zaratustra. O primeiro como professor do eterno retorno (Ewige Wiederkunft) e o segundo como defensor criador e afirmador da vida frente ao espírito de vingança e de ressentimento que assola a sociedade moderna, contrapondo-se, dessa forma, ao princípio conceitual de eternidade e a uma vontade fraca e decadente. “Nós, então, vemos mais claramente como Zaratustra, como o advogado da vida, do sofrimento, do círculo, é, ao mesmo tempo, o professor do eterno retorno e do além do homem"7 (HEIDEGGER', 1967, p. 419, tradução nossa).

\footnotetext{
${ }^{6}$ Embora se encontre, na maioria das obras dos comentadores estrangeiros, a tradução de Wille zur Macht do alemão e demais idiomas para o português como vontade de poder, optou-se por manter a tradução de Wille zur Macht por vontade de potência, mantendo a primeira tradução apenas nas citações dos comentadores utilizados na pesquisa. A existência de uma dupla tradução no termo Macht para o português não compromete o significado da expressão, como salienta Scarlett Marton, referindo-se à obra A doutrina da vontade de poder em Nietzsche, de MüllerLauter, ao descrever que: "Se traduzir Wille zur Macht por vontade de potência pode induzir o leitor a alguns equívocos, como o de conferir ao termo "potência" impulso e o vocábulo Macht, associado ao verbo machen, como fazer, produzir, formar, efetuar, criar. Enquanto força eficiente, a vontade de potência é força plástica, criadora. É o impulso de toda força a efetivar-se e, com isso, criar novas configurações em relação com as demais" (MARTON, 1997, p. 10-11). A opção por manter a tradução vontade de potência foi definida em detrimento das contextualizações da maioria dos comentadores e tradutores brasileiros pesquisados.

7 "We will then see more clearly how Zarathustra, as the advocate of life, of suffering, of the circle, is at the same time the teacher of the eternal recurrence of the same and of the super-man."

${ }^{8}$ Heidegger realiza uma interpretação da filosofia de Nietzsche, atribuindo a este o título de "último metafísico". Segundo Nunes (2000), a interpretação heideggeriana apresenta um fortalecimento à identidade de seu próprio pensamento, pois tanto a proximidade quanto o afastamento entre esses dois filósofos, são balizados pela interpretação de "extremidade" que a
} 
Religare, ISSN: 19826605, v.15, n.1, agosto de 2018, p.308-323.

Sendo assim, ao escrever no prólogo de Assim falou Zaratustra "eu vos ensino o super-homem. O homem é algo que deve ser superado, o que fizestes para superá-lo?" (Za/ZA, Prólogo), Nietzsche o faz tendo como respaldo a análise de seus contemporâneos que não compreendiam a abrangência da crise dos valores na qual se encontravam inseridos. Estes se encontram no meio de uma crise dos valores decorrentes da incapacidade de sustentar a crença em um ordenamento cósmico transcendente descrito por ele em A gaia ciência como sendo a morte de Deus, “ou seja, daquele Deus que é apreendido graças ao conceito" (PENZO, 2000, p. 30) e, respectivamente, pelo advento do niilismo. Com isso, a crítica de Nietzsche aponta para estruturação dos valores transcendentais. "Em suma, é toda a nossa cultura que é atacada" (HÉBER-SUFFRIN, 1994, p. 127).

O que se evidencia com a morte de Deus anunciada por Zaratustra é uma nova possibilidade de criação e de cultura. Assim,

a vida como ausência de Deus (Gottlosigkeit) conduz à afirmação da inocência do mundo e da liberdade criadora do ser humano. Redescobre-se a vida na vida, o mundo no mundo, inclusive o divino em Deus. Em outras palavras, reafirma-se o caráter imanente da vida e a superação de Deus como mero conceito ou valor moral. (RIBEIRO, 2010, p. 88).

Dessa forma, com a morte de Deus, o homem não mais recorre a um Ser absoluto, mas ao próprio homem. "A morte de Deus é, portanto, a situação que fundamenta a doutrina de Zaratustra" (FINK, 1988, p. 72). Sendo o eterno retorno à doutrina de Zaratustra, a proposta nietzschiana do além do homem é justamente a possibilidade que Nietzsche vislumbra para vencer o espírito de vingança, voltando o homem para uma fidelidade à Terra. Contudo, o filósofo constata, com a morte de Deus, a perda da crença de um valor metafísico objetivo, e não a perda da força da religião e ou da moralidade.

Na definição de Penzo,

filosofia nietzschiana apresenta. Para Oliveira (2004), Heidegger faz uma interpretação de Nietzsche não mais como histórico existencial, mas como ontologia. Nesta perspectiva, para Heidegger, em Nietzsche, se condensaria toda a história da metafísica. 
Religare, ISSN: 19826605, v.15, n.1, agosto de 2018, p.308-323.

isso não significa o crepúsculo da metafísica, mas apenas de uma metafísica objetiva. E, igualmente, não significa o crepúsculo de Deus, mas sim do Deus abordado com as categorias de uma lógica fundada no princípio de não contradição. Não se pode dizer que com a problemática nietzschiana se assista a uma crise do pensamento metafísico, mas que nos encontramos diante de um modo de ver a metafísica essencialmente como crise [...]. Tal metafísica, típica de um niilismo passivo, está na base de uma nova expressão cultural, que se funda na consciência do limite do conhecer e, portanto, numa cultura que é, enquanto tal, essencialmente crise. (PENZO, 2000, p. 14).

Para Nietzsche (Cf. FW/GC), enquanto a fé em Deus como um Ser transcendente perece perante as novas ideias modernistas, a religião mantém erguidos os princípios da moralidade e da razão. Com isso, a proposta nietzschiana é o surgimento de um tipo superior ao homem, capaz de afirmar e valorar a vida sem se reprimir pelos valores ético-religiosos da modernidade, mas suprimindo tais valores.

Nesta percepção, afirma Marton que:

para transvalorar os valores, é necessário suprimir o solo a partir do qual os valores até então foram engendrados; é preciso ter conhecimento da morte de Deus - e, em consequência, substituir a concepção de homem como criatura em relação a um Criador por outra, pela concepção de além do homem. Deixando-se de postular um mundo transcendente, é a este que se passa a tomar por critério de avaliação das avaliações. (MARTON, 2003, p. 28).

No início da fase madura do filósofo, evidencia-se uma sequência da sua crítica aos conceitos morais que imperavam na sociedade moderna, que fora iniciada com os espíritos livres e que, através da caracterização da vontade de potência, faz-se referência a uma transvaloração. Nesse viés, ocorre uma fiel interpretação de criação e destruição de seus valores, sua origem e abrangência. Para Nietzsche, esse processo teria de possuir como objetivo a condução do homem moderno para além de sua condição atual, proporcionando a ele seu ultrapassamento.

Nesse viés, Deleuze (1990) aponta que apenas a metade de sua trajetória ao atingir o meio-dia, sendo somente possível concluir o percurso através de uma 
Religare, ISSN: 19826605, v.15, n.1, agosto de 2018, p.308-323.

transvaloração de todos os valores (Umwertung aller Werte), novos e antigos, que são arquitetados pelo paradigma ético-religioso do cristianismo. Dessa forma, o surgimento do além do homem já pressupõe cumprida a incomensurável tarefa de transvaloração.

Para Nietzsche, a transvaloração de todos os valores somente é possível através do esforço que o homem deve exercer para buscar seu ultrapassamento e, com isso, sair da inércia e decadência do mundo cristão. Mas seria esse apontamento nietzschiano possível?

\section{A proposta de Zaratustra: apontamento nietzschiano frente à crise dos valores}

Evidenciamos que o além do homem é tido como proposta de ultrapassamento, mas também é concebido como forma de contrapor-se ao "niilismo negativo" que se originou com o cristianismo e condicionou a crise dos valores iniciada no século XIX. Nietzsche percebe que, a partir do anúncio da morte de Deus, o niilismo negativo começa a despontar com mais força sobre a sociedade moderna. A partir dessa constatação, Matos corrobora com a compreensão nietzschiana ao afirmar que

[...] o niilismo é apresentado como a ciência desse apagamento, como "a história deste grande desprendimento", o extremo rompimento com o lugar específico do homem, como uma mudança de centro, uma excentricidade que constitui o modo de notificação mais fundo do seu ser e a configuração, em ato, de sua vida. (MATOS, 2003, p. 143).

Em Assim falou Zaratustra, Nietzsche descreve que, para não se deixar contaminar com o niilismo, fazia-se necessário que o personagem capital da obra se isolasse em uma caverna. Ao sair da caverna, Zaratustra percebe que a existência dos valores não passava de uma imposição na qual os homens se submetiam em prol de sua afirmação, mas que acarretava em sua própria desvalorização. “Grande Astro! Qual seria sua felicidade se lhe faltassem aqueles 
Religare, ISSN: 19826605, v.15, n.1, agosto de 2018, p.308-323.

a quem ilumina? Faz dez anos que se aproxima da minha gruta e, sem mim, sem a minha águia e a minha serpente, estaria afadigado da sua luz e deste caminho" (Za/ZA, Prólogo).

Evidencia-se que esse processo de transformação a que se refere Nietzsche na obra de Zaratustra tem como meta afirmar a vida perante a Terra através do surgimento do além do homem. Contudo, os homens possuidores de um sentimento de ressentimento, de vingança e devido à sua condição de submissão não compreendem o propósito do surgimento do além do homem. O processo metamórfico descrito por Zaratustra e a situação em que os valores se encontram são questionados aos homens na praça do mercado, e também pelo personagem é anunciada a luta que deve existir entre esses homens e o último homem (letzter Mensch).

Para Nietzsche, o último homem é o homem do niilismo. Incapaz de sair de seu amesquinhamento e desprezar a sua própria condição. O último homem é a representação do homem que, estando em conflito com a crise dos valores vigentes na sociedade, não cria e não nega qualquer valor. Segundo Giacóia Júnior,

a figura do último homem é a caricatura satírica do ideal que animava a crença da moderna Aufklärung [reconhecimento]: a convicção de que nas vicissitudes da história é preciso reconhecer a laboriosa e heroica peregrinação do gênero humano, na curva de um progresso infinito, em busca do fim último de sua existência: a consecução da felicidade e da bemaventurança sobre a Terra, o advento glorioso do primado universal da razão e da justiça. (GIACÓIA JÚNIOR, 2003, p. 17).

O conceito de último homem é o conceito cristão de homem moderno que se apresenta como a confirmação dos fundamentos da moralidade e otimismo socráticos. Desse modo, dentre as tipologias descritas na filosofia de Nietzsche, o último homem é considerado pelo filósofo como a figura mais depreciável a que se faz referência em seu Zaratustra, um homem fragmentado. 
Religare, ISSN: 19826605, v.15, n.1, agosto de 2018, p.308-323.

Dessa forma, o filósofo apresenta sua doutrina do eterno retorno como forma de afirmação de valores que criam, destroem e se transformam e que, diferentemente da formulação cristã de igualdade dos homens, se constituem no ser humano afirmar a si mesmo, sendo essa autoafirmação compreendida na filosofia nietzschiana como condição primordial do homem de afirmação e valoração da vida e de fidelidade à Terra. Isso possibilitaria ao homem desprender-se de conceitos predeterminados e compreender a significação do além do homem.

Sobre a compreensão de Heidegger sobre o além do homem, descreve Motta:

O super-homem é um "ideal contingente constituído de um princípio dinâmico, o da superação, seu alvo é um esforço para ir além; desta maneira um estado de estabilidade e conforto nunca é alcançado". Trata-se da superação do niilismo. É um eterno estado de intensificação e de alegria, experiência da unidade de todas as coisas no momento, do "eterno retorno". Trata-se de querer a vida como ela é. (MOTTA, 2008, p. 6).

Para que o homem se permita ultrapassar a si mesmo e abranger a doutrina do eterno retorno, necessita-se que ele não esteja preso aos valores morais e/ou a sua hierarquização, compreendendo todo o gozo da afirmação "do devir [ritmada pela] afirmação do desvanecimento e da aniquilação" (EH/EH, O nascimento da tragédia, § 3) que oferece toda espécie de incerteza, o que acarretaria o surgimento do além do homem. Sobre o eterno retorno, afirma Nietzsche que essa é a "mais elevada forma de afirmação que se pode em absoluto ser alcançar" $(\mathrm{EH} / \mathrm{EH}$, Assim falava Zaratustra, §1). E juntamente à doutrina do eterno retorno exerce-se na filosofia de Nietzsche, como força que a anima, a vontade de potência, que resultaria, como descrito por Zaratustra no capítulo "Da vitória sobre si mesmo", como a fundamentação da vida que se contrapõe à moralidade. Sobre essa contraposição, Vattimo descreve que

[...] a moral sempre condenou a explícita vontade de poder dos dominadores, dos transgressores ou reformadores da moral. 
Religare, ISSN: 19826605, v.15, n.1, agosto de 2018, p.308-323.

Uma vez descoberto que tudo é vontade de poder, todos são obrigados a tomar posição: já não existe, para os fracos e falhados, a proteção da moral, que lhes forneceu a base para desprezarem e condenarem os fortes. (VATTIMO, 1990, p. 78).

Sendo assim, "vontade de poder e eterno retorno confirmam um novo modo de conceber o mundo" (RIBEIRO, 2004a, p. 176) frente ao caos da crise dos valores. Nietzsche afirma que, sendo a vida uma constante luta, cabe ao homem afirmá-la, valorá-la ou não; somente possível através de uma força que a anima.

Mas o que é a vida, então? Isto confiou a vida mesma a Zaratustra, o caminhante, o convalescente: "eu sou o que tem que se supera sempre a si mesmo". A vida é superação, ultrapassamento, luta. Não é repouso, não é paz, mas luta, guerra e devir. Vontade de contradição e adversidade. A vida quer a superação de si mesma, quer o ocaso e novas auroras. Não quer conservar-se. Por isso não pode ser vontade de conservação e de vida o que quer, mas, na superação de si, querer o poder mesmo querendo seu ocaso. Devemos ser capazes de um nobre querer. Aqui se faz justiça ao que é. O que é assim, portanto, uma luta de forças pelo poder. (RIBEIRO, 2004b, p. 278, tradução nossa) ${ }^{9}$.

Contudo, o que podemos perceber na filosofia nietzschiana é que a ideia de criação desse tipo superior ao homem acompanha toda a sua trajetória, desde o gênio até o além do homem, resguardadas algumas diferenças, pois segundo Araldi

o projeto de criação do gênio fica restrito ao domínio estético nos escritos da época do nascimento da tragédia, no Zaratustra a criação do além do homem (Übermensch), que procura unir as propriedades do artista (afirmador da vida) e do conhecedor (pessimista do intelecto), tem um caráter singular. O Übermensch cria a partir de si mesmo, de seu excesso de sabedoria, de prazer e dor; ele não serve mais a nenhum propósito retentor da

\footnotetext{
9 "Pero, ¿qué es la vida, entonces? Esto se le ha confiado la vida misma a Zaratustra, el caminante, el convaleciente: "yo soy el que tiene que superarse siempre a sí mismo". La vida es superación, sobrepasamiento, lucha. No es reposo, no es paz, sino lucha, guerra y devenir. Voluntad de contradicción y adversidad. La vida quiere la superación de sí misma, quiere su ocaso y nuevas auroras. No quiere conservarse. Por eso no puede ser voluntad de conservación y de vida lo que quiere, sino en la superación de sí querer el poder aunque sea querer su ocaso. Hay que ser capaz de un noble querer. Aquí se hace justicia a lo que es. Lo que es así, una lucha de fuerzas por el poder."
} 
Religare, ISSN: 19826605, v.15, n.1, agosto de 2018, p.308-323.

vontade [...]. Nele um tipo de "sujeito" (selbst) assume sua autonomia e centralidade na criação [...]. (ARALDI, 2008, p. 92).

Podemos considerar que a ideia de criação de valores em Nietzsche é uma atitude reflexiva à arte, que, igualmente à proposta do além do homem de afirmar a vida, vivencia a vontade de potência. Na definição de Machado (1999a), a criação não é mais conferida à ilusão e/ou à aparência, mas ao homem propriamente, acarretando-o ir além de si mesmo, em que a existência dos gênios (apolíneo e dionisíaco) da época de O nascimento da tragédia ainda conserva-se no período do Zaratustra. Na afirmação de Araldi (2008, p. 92-93), “Zaratustra se move ainda entre o abismo dionisíaco (do qual ele procura fugir) e o reino humano das aparências, ilusões e enganos, ou seja, o mundo da arte (antes compreendida como arte apolínea)".

Da mesma forma, sobre a arte em Nietzsche, Vattimo afirma que apesar dela dizer respeito à tragédia, 10 "aqui ela se torna sinônimo de toda arte sã porque o gosto pelo trágico é apenas possível para quem não tenha necessidade de soluções finais; portanto, para quem saiba viver no horizonte aberto do mundo como Wille zur Macht e eterno retorno" (VATTIMO, 1990, p. 87). A arte é possuidora de características transformadoras à condição desprezível do homem em uma condição favorável. Para Nietzsche, a arte em Zaratustra é a vontade de potência e o eterno retorno que se manifestam sobre a condição do amor fati.

Zaratustra é descrito como um dançarino e também um cantor embriagado do eterno retorno frente à crise dos valores. Sobre Zaratustra e seu contexto, Machado diz que

Zaratustra cantor e dançarino que canta ebriamente em sua "cantiga de roda", que seu mundo atingiu a perfeição [...], o Zaratustra que se torna um filósofo dionisíaco, é aquele que tem a mais dura e terrível percepção da realidade e ao mesmo tempo não vê nisso nenhuma objeção contra o eterno retorno da vida [...]. Deste modo, quando penso que Assim falou Zaratustra é uma tragédia estou querendo dizer que, na estrutura poético-

\footnotetext{
${ }^{10}$ Nietzsche, a partir de A gaia ciência, descreve a tragédia com um significado mais abrangente, não se prendendo apenas ao conceito teatral ou artístico do termo.
} 
Religare, ISSN: 19826605, v.15, n.1, agosto de 2018, p.308-323.

dramática desse livro que Nietzsche considerou sua obra mais importante, Zaratustra, seu personagem central, é a princípio um herói fundamentalmente apolíneo que, no final de um processo de aprendizado, em que deve enfrentar o niilismo em suas várias formas, assume seu destino trágico, isto é, diz sim à vida como ela é, afirmando poeticamente seu eterno retorno. (MACHADO, 1999a, p. 80).

Evidencia-se que Nietzsche, para compreender o além do homem como um tipo superior, teve que passar por um processo de aprendizado que se iniciou em seus primeiros escritos, com a concepção dos conceitos de criação e destruição. Posteriormente, estabeleceu uma contraposição à cultura e tradição do cristianismo, herdando a crise das afirmações dos valores frente às ideias modernas, culminando na criação de um tipo superior ao homem que não se encontra vinculado a nenhum valor descrito pelo processo histórico, propenso ao niilismo descrito pelo filósofo como afirmativo.

\section{Considerações finais}

Ao observar as colocações apresentadas, podemos considerar que a apresentação do homem como ponte entre o animal e o além do homem, descritas por Nietzsche em seu Zaratustra, solidifica a busca pela auto superação, sendo esta, uma proposta do pensamento amadurecido alcançado pelo filósofo - $\mathrm{O}$ Übermensch - onde à criação de novos valores polemizaram sua filosofia.

Em sua definição sobre o Übermensch é apresentado três apontamentos sobre os quais se funda a compreensão de seu Zaratustra. Acompanhando esse pensamento, Nietzsche apresenta um processo hierárquico nos ensinamentos de Zaratustra, pois o personagem anuncia a todos o Übermensch, para alguns a vontade de potência, mas somente para ele mesmo o eterno retorno.

Toda essa discussão, caracterizada pelo niilismo e o conflito da afirmação de valores transcendentes, constitui como uma nova possibilidade de afirmação cultural ocidental. Em razão do exposto, percebe-se o niilismo na filosofia nietzschiana como uma lógica da decadência e não uma causalidade. A vontade 
Religare, ISSN: 19826605, v.15, n.1, agosto de 2018, p.308-323.

niilista se manifesta na negação e por meio dela sua condição de vontade de potência. Conquistando ascendência sobre a força que se contrapõe. Ou seja, a busca do Übermensch é a busca de um ser criador que estabelece novos valores, a exemplificação da busca pelo ultrapassamento do homem frente à crise dos valores que são ressaltados no último período da produção filosófica de Nietzsche.

Respectivamente, a morte de Deus é um aprofundamento das ideias e não uma ruptura, uma preparação para o anúncio do Übermensch. A busca do Übermensch é a busca de um ser criador que estabelece valores desvinculando do processo de divinização do mundo estabelecendo uma concepção de conceito de valor que constitui uma crítica à crença (Glaube) de valores absolutos, uma transvaloração que nos indica uma nova forma de valorar e criar que abre a possibilidade para uma nova perspectiva de se compreender o mundo. De um mundo sem a necessidade de uma moral reguladora, um Deus para criá-lo, guiálo ou até para destruí-lo, sem encantamentos.

Contudo, para melhor compreendermos essa percepção nietzschiana, fazse necessário distinguir sua concepção de criação e destruição de valores. O que é melhor elucidado pela definição de niilismo dentro de sua produção filosófica que na tradição dos estudiosos de Nietzsche, o conceito caracteriza-se por uma ambiguidade.

Nesta perspectiva, o pensamento nietzschiano atravessa pelos paradigmas de uma sociedade cristianizada declinada ao niilismo por natureza. Em Nietzsche, o niilismo é definido por negativo, que seria o niilismo inacabado, não podendo jamais ser uma transvaloração dos valores, e por niilismo afirmativo que direciona sua finalidade para a destruição da moral e dos valores transcendentes, o que levaria o homem a negar os valores absolutos, e por sua vez, ver a vida como um eterno retorno. Compreendendo assim, a não existência da eternidade ou de um mundo superior pregado pelo cristianismo onde este processo é conduzido pela vontade de nada, pois a vontade niilista se manifesta na negação e por meio dela sua condição de vontade de potência. 
Religare, ISSN: 19826605, v.15, n.1, agosto de 2018, p.308-323.

Em conformidade com essa diferenciação entre niilismo afirmativo e negativo, concluímos que o entendimento de ultrapassamento do niilismo proposto por Nietzsche (Cf. Za/ZA; EH/EH; FW/GC), ou seja, a proposta de superá-lo, se dá dentro do próprio movimento gerado por sua dinâmica. O que o reafirma como um movimento de força impulsionador da vontade do homem vivenciado durante todo o processo histórico da civilização.

Devido o exposto, podemos afirmar que o cerne da crítica nietzschiana perpassa por toda a história e identidade cultural da sociedade ocidental. Todavia, ela "se atesta de modo mais persistente e significativo no registro da crise cultural que atravessa o século $X X$, sob o signo da qual irrompeu o século XXI" (GIACOIA, 2013, p. 254).

Portanto, a filosofia nietzschiana descreve um novo ponto de vista para a compreensão desse fenômeno cultural que perpassa pela estruturação da sociedade ocidental, caracterizado pela perda e desvalorização dos valores absolutos. O ultrapassamento proposto pelo filósofo nos remete a compreender o niilismo como tudo aquilo que se deve aguardar e almejar, não o interpretando como um episódio, mas como o impulsionador da nossa história.

\section{Referências}

ALMEIDA, Rogério Miranda de. Eros e Tânatos: a vida, a morte, o desejo. São Paulo: Loyola, 2007.

ARALDI, Clademir Luís. As criações do gênio e do além do homem: Nietzsche em transição. In: PASCHOAL, Antonio Edmilson; FREZZATTI JR., Wilson Antonio (Org.). 120 anos de Para a genealogia da moral. Ijuí: Unijuí, 2008.

DELEUZE, Gilles. Nietzsche. Trad. de Alberto Campos. Rio de Janeiro: Edições 70, 1990.

FINK, Eugen. A filosofia de Nietzsche. Trad. Joaquim Lourenço Duarte Peixoto. 2. ed. Lisboa: Presença, 1988.

GIACOIA JÚNIOR, Oswaldo. Nietzsche: o humano como memória e como promessa. Petrópolis: Vozes, 2013.

. O caos e a estrela. Impulso/Revista de Ciências Sociais e Humanas, v. 19, n. 28, out. 2003. 
Religare, ISSN: 19826605, v.15, n.1, agosto de 2018, p.308-323.

HÉBER-SUFFRIN, Pierre. O "Zaratustra" de Nietzsche. Trad. Lucy Magalhães Rio de Janeiro: Jorge Zahar Editor, 1994.

HEIDEGGER, Martin. Who is Nietzschee s Zarathustra? Review of Metaphysics, v. 20, n. 3, p. 411-431, Mar. 1967.

MACHADO, Roberto. Zaratustra, o apolíneo e o dionisíaco. In: PIMENTA NETO, Olímpio José; BARRENECHEA, Miguel Angel de (Org.). Assim falou Nietzsche. Rio de Janeiro: Sette Letras, 1999a.

MARTON, Scarlett. A terceira margem de interpretação. In: MÜLLER-LAUTER, W. A doutrina da vontade de poder em Nietzsche. Trad. de Oswaldo Giacoia Júnior. São Paulo: Annablume, 1997.

. Em busca do discípulo tão amado: uma análise conceitual do prólogo de Assim Falava Zaratustra. Impulso Revista de Ciências Sociais e Humanas, v. 19, n. 28, out. 2003.

MATOS, Junot Cornélio. Críticas nietzschianas à modernidade. Impulso/Revista de Ciências Sociais e Humanas, v. 19, n. 28, out. 2003.

MOTTA, Manoel Barros da. Nós inventamos a felicidade! Sobre Nietzsche e Jacques-Alain Miller. Latusa Digital, ano 5, n. 35, dez. 2008.

NIETZSCHE, Friedrich Wilhelm. A gaia ciência. Lisboa: Guimarães Editores, 1996. (FW/GC)

Assim falou Zaratustra: um livro para todos e para ninguém. Trad. Paulo César de Souza. São Paulo: Companhia das Letras, 2011. (Za/ZA)

. Ecce homo: como alguém se torna o que é. Trad. Paulo César de Souza. São Paulo: Companhia das Letras, 1995. (EH/EH)

. Genealogia da moral. Trad. Paulo César de Souza. São Paulo: Companhia das Letras, 2006. (GM/GM)

. O anticristo. Trad. Paulo César de Souza. São Paulo: Companhia das Letras, 2007. (AC/AC)

- O nascimento da tragédia. Trad. Paulo César de Souza. São Paulo: Companhia de Bolso, 2008. (GT/NT)

. Sämtliche Werke. Kritische Studienausgabe (KSA). Herausgegeben von Giorgio Colli und Mazzino Montinari. München/Berlin/New York: dtv/Walter de Gruyter \& Co., 1988. (15 Einzelbänden).

NUNES, Oliveira. O Nietzsche de Heidegger. Rio de Janeiro: Pazulin, 2000. 110

OLIVEIRA, Ibraim Vitor de. Arché e Telos: niilismo filosófico e crise de linguagem em Fr. Nietzsche e M. Heidegger. (Doutorado em Filosofia). Roma: Pontificia Università Gregoriana, 2004.

PENZO, G. O divino como problematicidade. In: PENZO, G.; GIBELLINI, R. (Org.). Deus na filosofia do século XX. São Paulo: Loyola, 2000.

RIBEIRO, Flávio Augusto Senra. Culpa e responsabilidade em Nietzsche. Horizonte, Belo Horizonte, v. 3, n. 5, p. 169-178, 2º sem. 2004a.

. Culpa y responsabilidad en Nietzsche. Tese (Doutorado em Filosofia).

Madri: Universidad Complutense de Madrid, 2004b. Disponível em: <http://eprints.ucm.es/tesis/fsl/ ucm-t27808.pdf>. Acesso em: 15 Set. 2011. 
Religare, ISSN: 19826605, v.15, n.1, agosto de 2018, p.308-323.

Deus na filosofia nietzschiana. In: OLIVEIRA, Ibraim Vitor de; PAIVA, Márcio Antônio de (Org.). Violência e discurso sobre Deus: da desconstrução à abertura ética. São Paulo: Paulinas, 2010. 111

SILVA, Vagner. A tipologia nietzschiana. Dialogia, v. 7, n. 1, p. 103 - 112, 2008. Disponível em:

<www.uninove.br/PDFs/Publicacoes/dialogia/dialogia_v7n1/dialogia _v7n1_4h08.pdf> Acesso em: 20 maio 2012.

VATTIMO, Gianni. Introdução a Nietzsche. Trad. de António Guerreiro. Lisboa: Presença, 1990. 